\title{
CHALLENGES TO ADMISSIONS IN THE EXTENDED CURRICULUM PROGRAMME IN THE FACULTY OF BUSSINESS AND MANAGEMENT SCIENCES
}

\author{
T. M. Leshoro* \\ e-mail: Leshorot@cput.ac.za;
}

\author{
A. Jacobs* \\ e-mail: Jacobsar@cput.ac.za \\ *Department of Public Administration and Governance \\ Cape Peninsula University of Technology \\ Cape Town, South Africa
}

\section{ABSTRACT}

The Extended Curriculum Programme (ECP) of the Faculty of Business and Management Sciences (FBMS) faces challenges at the beginning of every year. The major constraints and sources of these challenges emanate from the application, admission and registration processes for the programme. The challenges are primarily thought to be origination from the structure at the high school level where little of computer knowledge is passed on to learners, critically so for students from rural structures where there are no facilities. Articulating from high school to university becomes a problem for the learners from these schools without adequate facilities. Consequently, both the lecturers and the new entrants meet with serious problems resulting from cognitive dissonance, with the ECP students feeling left out in the transition. The generality of the educators in the townships and indeed the rural schools have serious challenges with computers, and hence they have no computer technology skill to pass on to the high school finalists as they prepare for transition to tertiary education. The article proposes a different context-relevant approach for the application, admission and registration process as it affects first year ECP applicants. Changes to the admission policy to make it compulsory for all admissions to be concluded at the same time, would reduce the failure rate of these students who are ill prepared for tertiary education and still join university late in the semester. Specifically, the rural learners as they "transit" from high school to tertiary education without adequate preparation. Setting up fixed admission dates and cut-off times for the processes would enable the learners to start together with other system in time to avoid failure rates.

Keywords: Extended Curriculum Programme, application and admission procedure, registration procedure, lecturing times, cognitive dissonance, at risk students

\section{INTRODUCTION}

The Extended Curriculum Program [ECP] is a government initiative to enable disadvantaged 
students that do not pass well not passing well, but presumed able, to enter into university. The current situation in the country is that only two out of every ten high school (Grade 12) learners make it through graduation in university. ECP was therefore designed to assist in boasting numbers of black students that go through university by providing special admission requirements. South Africa is 80 per cent rural suggesting therefore that the large number of applicants into the university are rural (Boughey 2007, 5-13; Scholtz and Allen-Ile 2007, 10). Regardless of the large amounts of government money put into education, the system of education in South Africa remains highly problematic. The disparity between the standards in the urban settings and those in the rural settings only confirm former President Thabo Mbeki's assertion that South Africa is one country with two nations. These ill prepared high school graduates either apply early in the previous year or appear as walk-ins for admission. This admission process is the focus of this study with specific emphasis on the ECP students who are presumed at risk before they start university (Van der Flier, Thijs and Zaaiman 2003/6, 399409). The admission system of the university is extended too often beyond the planned closing dates, presumably to fill in existing spaces. The admission process therefore extends to the writing of the first term papers with many students joining classes at examination time. The contact classes meant to assist students with the learning process are therefore not provided to the late admissions. The ECP students are presumably disadvantaged and considered as "at risk" students who would need more assistance from lecturing. The admission system therefore provides an uncomfortable situation with lecturers having to go back to revise work that has been taught in class. Generally, the results of the "late-entry" ECP students are poor and this is a concern for both the university and the lecturers. This article seeks to identify causes of the delayed registration for these "at risk" students given the extent to which a syllabus has been covered by the time they are admitted (Badat 2010, 9; Shay, Wolff and Clarence-Fincham 2016, 23-24).

\section{ADMISSIONS AND REGISTRATIONS}

It is very important that criteria for the admissions and registration for the ECP new students be revisited in order to avert the problems that are usually experienced from the beginning of the year. The students who register for the ECP programme are largely late applicants or walkins who usually apply in January or February. ECP is a foundation programme which has been established to help struggling students to gain access to higher education and it is mainly for those students with inadequate preparedness which originate from poor high schools (Boughey 2007, 5-13). These strugglers, need not to be admitted into the Mainstream but directly into the ECP as they stand a better chance of succeeding and improving over a period of 4 years. If they 
are put straight into the Mainstream, they are mostly bound to fail. Most of the students with inadequate preparation end up dropping out at $1^{\text {st }}$ year and never coming back and those who stay-in, far less than 50 per cent reach graduation point (Scholtz and Allen-Ile 2007, 10-11; Jones et al. 2008, 20). The problem with ECP students, is bad preparation from high school level and that end up leading to a high level of dropping out at university level. Thus, the Matric scores should be tightened-up so as to prepare the prospective students for university education. The better the results, the better the chances for the student to succeed at university level. The other aspect that needs to be taken into consideration, is that the teaching of Mathematics and Science at high school, needs to be improved and be done by well qualified teachers as these two subjects are very pivotal at university level. In reality, the ECP ends up with bad students because of bad preparation from high school. Thus, the issue of good preparation at high school, can really help the ECP students in adjusting very quickly at university level. The Mainstreamers in this regard, turn to settle in much quicker than their counterparts as their admission and registration gave them no hassles at all (Van der Flier et al. 2006, 399-409).

The ECP students are being accepted into the system with lower marks than their counterparts in the Main Stream. Both groups do the same subjects but over different periods of time and they also write separate examination papers. The papers they write are both from the same subject but the issue here is that the ECP students receive more support through extra responsive teaching (Garraway 2009; HELTASA 2009).

\section{THE MATRICULATION RATING ANALYSIS}

It should be realised that ECP caters mainly for the students who are not yet fully ready for the university level of education. According to the Performance Indicators for the Benchmark Tests, the Main stream students turn to have higher passing percentages than the ECP students, but the difference is not that much. In most cases, the Mainstream group do manage to pass all their subjects for that particular academic year. ECP have the most risk students than the Main stream and the main reason being their bad or rather lower results at Matric level (Scholtz and Allen-Ile 2007, 19). There is a certain average score that a candidate needs to get at Matric level in order to be admitted into a National Diploma or a University Degree. All in all, a student needs to receive very good marks at Matric to stand a better chance of being admitted at university level i.e. at least level-4 in each subject. Acceptance into university also depends on the requirements of that particular department as admission differs accordingly i.e. department by department. Thus, at CPUT admission needs to be changed so as to avoid a high rate of failure/dropout. It is better that CPUT should adhere to the NBTs in assessing the student preparedness for university education, as that will help students to complete their 
diplomas/degrees in record time, at the most likelihood (Garraway 2009; HELTASA 2009; Foxcroft 2006, 7-14).

Admission requirements are based on Matriculation results i.e. how good are they. Thus, according to Yeld (2006, 17-18) bench marking should be embarked upon so that quality and nor quantity is maintained at university level. For instance, at CPUT if a student is intending to enrol for a National Diploma in Nature Conservation, then that student need to at least have level-4 grade in English, Life Science as well as Mathematics. Thus, for every course of study, there is a criteria for admission or acceptance. High scores in this regard will stand a candidate in good stead to be admitted without any hassles. Thus, the issue of admission should strictly be adhered to and not to be compromised as any compromise might bring admissions disorder (Boughey 2007, 5-11; Griesel 2006, 1-6).

\section{ECP STATISTICS 2015}

Statistics provided by Mr Tshaka, the current Co-ordinator of ECP in the FBMS, from the previous years need to be revisited before coming up with any comprehensive conclusions or recommendations. Apart from the gloom and challenges within the ECP especially for the 2015 academic year, enrolments have been on the increase as compared to the previous years

- 2013: 253 students

- $\quad$ 2014: 304 students

- 2015: 386 students.

The above numbers are an indication that irrespective of the already mentioned challenges for both lecturers and students in the ECP, the students' numbers have increased by 153 per cent between 2013 and 2015. However, Enrolment breakdown by department 2013-2015:

\begin{tabular}{|ll|ll|}
\hline Sport Management & $6 \%$ & Marketing & $8 \%$ \\
\hline Management & $9 \%$ & Events Management & $9 \%$ \\
\hline Tourism Management & $9 \%$ & Entrepreneurship & $10 \%$ \\
\hline HR Management & $11 \%$ & OMT & $11 \%$ \\
\hline Public Management & $11 \%$ & Accounting & $16 \%$ \\
\hline
\end{tabular}

As can be seen from the stats above, the composition of ECP numbers by department is uneven for the period 2013-2015. The allocation of places available needs to be rationalised within the faculty and targets for each department set. The growth trajectory for the entire faculty also needs to be mapped as currently not all departments are representing the ECP. There is also talk 
of making all mainstream diploma courses 4 years instead of 3 years. This will also impact on the current conceptualisation of ECP as well as the future size and shape of the ECP.

Apart from the above percentages from all the departments within the Faculty of Business Management Sciences, the registration and admission challenges still remain and need to be addressed as soon as possible in order to remedy the situation in future (ECP Statistics 2015).

The above information, justifies that the admissions policy need to change, and that is based on a number of academic aspects. Firstly, the Extended Curriculum Programme allows students to gain access to higher education i.e. students from poor schooling background. These students in their Grade12 exams, just managed to make it through but not being good for university education. Their pass rate is not good enough for them to gain automatic entry into university system especially the Main Stream. This programme is established in order to help them adjust from high school to university standards. (Van der Flier, Thijs and Zaaiman 2003, 405-409). The students in the ECP, are being selected on the basis of the marks they achieved in their Matric examination i.e. marks according to each subject especially in Mathematics.

Transition from high school to university level of study, is not that smooth irrespective of the subject they are studying for. Thus, the shortcomings of these students at high school, if not corrected early at university will end up leading to high dropout; hence the introduction of the ECP as a mechanism to help these students. Some reasons might be pointed at late application for admission or late decision to apply to enrol at university. Some of these ECP students are exceptionally brilliant e.g. in their command and writing of English which in any case is not even spoken in most of their homes. (Scholtz and Allen-Ile 2007, 920-921).

\section{CHALLENGES IN THE ECP}

Because of the state of our high school educational system, fewer students after passing their National Senior Certificate qualify for direct entry into the university system/education. The most problematic subjects in this programme is the Science/Mathematics. The problem actually starts with the teaching standards at high school which are the result of no good system of education. Again, the teachers at high school, most are not well trained and not well equipped to teach the Science and Mathematics, hence the bad results in the examination. It is not easy to accept this, but it is a fact of reality. Thus, ECP helps the ill-prepared students to adjust to university standards (Scholtz and Allen-Ile 2007, 920-921).

Thus, according to Scholtz and Allen-Ile again $(2007,921)$ the ill-preparedness of the students in physical science and mathematics from high school, lead to their poor performance at university and that in the long run will lead to poor or no expertise at all in these two fields. High failure rate then affects the throughput (number of completions). Thus, this is the 
programme designed at bridging the gap not only in these two subjects but all other subjects that have bad results for the students. Then that is where ECP comes in (Ogle 2010, 1-2)

Thus, according to Scholtz and Allen-Ile (2007, 921-922), if the policy is amended, it will need to reflect the following; the high rate of success in the ECP and secondly, the students' ability to adjust to the university standards should be evident through their capability with their schoolwork. What needs to be taken into consideration, is that not only Mathematics and Physical Science, but all other subjects offered in the ECP should be well looked after as the career paths of students are not the same. All other subjects are needed in order to have a complete curriculum. Thus, if the policy is amended, it should reflect success in the pass rate of students within the ECP and the throughputs should be higher every year. Now the findings on ECP was that the proficiency tests have been conducted under SATAP in order to test the students' preparedness for university and also identifies the students who might need assistance to adapt to their studies (Badat 2010, 10).

\section{THE RECOMMENDATIONS OF THIS ARTICLE}

The authors of this article have identified a number of tentative proposals which may be implemented in trying to remedy the current situation. The main challenge that emerges with the ECP admissions and registration do not affect the lecturers and students only but reflect negatively on the university at large. This situation needs to be led by the Dean and the Faculty Manager as ECP falls within this faculty. The departments within the faculty, who have ECP programmes, need also to come up with strategies as to how best to help sustain and grow this programme.

The authors feel that matric results are insufficient in placing these students and diagnosing their specific needs. There should be some consideration of factors other than matric scores which will be more helpful in supporting our students. For now, the first step, should it be possible, ECP and Mainstream registration should be done or take place simultaneously to avoid class attendance delay. The second step should be that both groups be allocated equal spaces on the system although the ECP students are on most occasions in the minority. The main reasoning in this regard is that whatever space is left from the mainstream can quickly be allocated to the walk-ins. This help to avoid late registration a lot. The deadline in both streams should be the same and ECP should be firm on that. Thus, in order to resolve the ECP's admission problems, we need first to solve the general admission challenge of the entire institution to see where the actual challenge emanates and what can be done to try and resolve it.

Another point is that students should be taken on merit and not just to fill in the empty 
spaces. Students taken on the just filling up spaces will at the end of the day end up failing and that might lead to lecturers being forced to partly take the blame as to what did they do or not do in helping those students not to fail. In cases like this, the lecturers cannot do anything as the students did not pass well from high school. The institution should avoid the question of "Do we take students for access or success?" This question needs to be seriously considered before students can be accepted into the ECP programme as if it is brushed aside, it will dent the image of not only ECP, but the institution as a whole.

Furthermore, the authors suggest that both the Dean and the Faculty Manager should allocate the HoD of the ECP admission/approval powers to fast track the registration of ECP students. If not, then both should develop a method or strategy of improving the registration problems within the ECP. Before anything can be decided in relation to the ECP students, it should be taken into serious consideration that whatever decisions being made in relation to ECP students, it is the name of the institution that is in the centre, be it positive or negative.

The issue of admissions and registrations, affect both the Lecturing staff as well as the students. There has been a number of reflections on the side of the students which paint a very bleak future for them especially the very new students who do not know anything about university life. One of the lecturers in the ECP programme; Ms Carse, further indicated that after the issue of registration has been resolved, then springs up another problem of accommodation which needs to help the students with a proper place to study. The students do indicate that if they do not have a conducive place to study, they face imminent failure at the end of the year and thus adding to the statistics of dropouts. Ms Carse further in 2015, indicated that some students do end up falling sick as well as being depressed albeit being admitted into the university and at times, lead to them abandoning their studies. Worse part of it, is that the university does not have the facilities to deal with such problems that the students do experience albeit having succeeded in registration. At the end of the entire series of problems, the lecturing staff does not know what to do with such student's problems and become affected too. Thus, we end up with both parties being affected although from different angels i.e. the students as well as the lecturers. Lecturers are further faced with the problems of how many students are they going to have in the end as the numbers keep on changing daily due to the unending admission and registration programme. Furthermore, the lecturers, are being frustrated by the fact that with a batch of new students, they have to start from scratch and thus seeing no progress at all and appearing to be unfair to the students who registered early or on time.

The problems faced by the lecturing staff, are very enormous and some include the unending absenteeism which on its own, has many connotations e.g. lack of money to come to school or even no place to stay and study conductively and all that, leaves the lecturer in limbo 
of not knowing whether the student is coming back or not. One of the most taxing aspects of students and lecturers, is that the lecturing staff are constantly guarding against the aspect of students failing as that in the end reflects badly on the very lecturers as if they are unable to teach the students properly. All that in the end, affect the pass rate at the end of the academic year. Thus, an improved application and registration process would see a corresponding increase in the pass rate. The university should help halt this problem and that can be done by addressing it at the beginning of the registration period. The lecturers should not be seen as if they have set poor students for failure. Thus, the system should be overhauled in order to help both lecturers and students, so that each should be able to meet their intended targets and that is all about the high pass rate.

The university need to be very strict on the deadlines for admission within the ECP as that in the end, puts more pressure on the lecturers and the students. The ECP on its own as it has been said before, caters for students from poor schooling background and they need to have enough time to acclimatise with the standards being required for coping the higher education levels. Most if not all, do not use English as their home or rather first language and that impedes on their progress in their studies. Furthermore, some of their high school teaching staff are not well equipped in teaching some of the subjects highly required for university standards such as English and Mathematics. These high schools are sending over half cooked products to university and thus the blame cannot just be placed on the students as if they could have been taught by well-equipped teachers, then they could not be presenting the universities with language problems. Now at university, the lecturers are forced to try and teach the students the English language as well as sentence construction which they should have done at high school level. This in itself, is a drawback which needs that the Government should take full notice of.

Thus, it is suggested by the authors that the old teachers training colleges should be revived and some of the old methodologies of the previous system of education be copied as some of the then strategies and tactics, were very effective at high school level, hence in the past students at first year level did not struggle as do the present crop of first year students. Those now closed colleges used to produce well or rather highly trained teachers who in turn, produced very well and capable students. The country with all its resources, cannot produce quality students and it is not that it cannot, but the problem is that of less equipped teachers at high school. If the teachers are well trained, then they will be in a position of producing very excellent students who are university material and they will be able to cope up with the pressures of studying at a higher level. We do not recommend everything of the old system but in its wake, it managed to produce most of the current academics, of which they can stand firm on both their feet if the need arises. Some of the things that could be learned from the old system, was how to study, 
how to write an essay as well as proper language construction in English which is a big problem on the current first year students.

\section{THE FINDINGS OF THIS ARTICLE}

The findings of this article are based and are emanating from the very admission policies which need to be reviewed. The admission policies need to indicate the fluid system of acceptance. It should be clearly understood that the ECP deals with two categories i.e. those who apply early but their results are not that good and are being admitted into the ECP and the walk-ins. These two categories are the same but the difference is that the latter did not apply at all and just apply physically. It is this group which really throw the issue of admission into total disarray. The issue of these students if not attended to, will bring unending problems for the entire education system in general. The point here is that these students take longer than all others to register and in the end, they end up starting later than the rest in attending classes and ultimately delay everybody.

The issue of walk-ins is still ok, but it needs to be under tight control otherwise it will lead to unending admission and registration. For instance, once the walk-ins are taken in, their on the spot applications need to be captured and that in itself, is a lot of work. Again, those applications need to be processed. Still, the walk-ins never stop coming to look for admission albeit their results which do not qualify them for acceptance. That in itself, is a problem which the walk-ins fail to understand and accept. So such circumstances lead to the undermining of the ECP in that it is a lower level of study as it accommodates students with lower Matric results.

For as long as all what have been listed and proposed above, is not taken or attended to seriously, the ECP will be taken as a dumping zone for dull students and admission problems will always be there. These problems are not for CPUT only, but nationally for all universities with ECP curriculums. Thus, the authors recommend that with walk-ins as they are the majority in the ECP, be given the NBT before being accepted and those who pass the NBT's will automatically become accepted. Both authors who are lecturing in the Business Faculty of CPUT, think that this will lessen the issue of late registrations, class attendance and the late start of the academic programme for these students. Those who failed the NBT will have to accept their fate. That will lessen further the stress and hope of being accepted into the university/ECP. The issue of university admission and registration is not as easy as it might appear to be.

Thus, this article is trying to show that any institution of higher learning need to be very firm on application and registration deadlines and need not to compromise on those aspects. 
The relaxed policies on those two aspects, will lead from one problem to another thus in the interim, lead to the start of the academic year being delayed by something which could have been avoided if strict rules were followed from the beginning.

\section{THE CONCLUSION}

In concluding this article, the authors would like to state that the admission policy as well as the registration need to be changed in order to improve the chances of the academic year starting on time. The starting of the academic year on time, will help to alleviate a number of problems such as unending registration and confusion of the students who even after being registered, are still in limbo about where to find and attend classes. Furthermore, the university need to have a cut-off date where they are not going to entertain any issue in relation to admission and registrations. The university should take the blame for the chaos of every beginning of the year problems which then hamper the early start of the academic year. What needs to be realised, is that if the academic year begins late, then the possibility of completing the syllabus on time is very slim. What ends up taking place, is that everything will be done under immense pressure, to the disadvantage of both the students as well as the lecturers. The end result of this pressure to complete the syllabus, will be a high failure rate on the side of the students at the end of the year. The university enrols as many students as possible with the hope that many will attain their qualifications as soon as possible and not to produce a lot of failures. So it is the university which needs to protect its own integrity of not producing failures of students but students who pass. The most important issue in this regard, is the throughput at the end of the year i.e. the number of students who have passed need to improve on a yearly basis and not to drop. The institution thus needs to take the prerogative on insuring that as many students as possible, do pass and on merit and not for the sake of passing. All this is possible only if the university addresses what the authors have highlighted or else the admission problems will remain for a long time to come.

\section{REFERENCES}

Badat, S. 2010. "The challenges of transformation in higher education and training institutions in South Africa." Paper commissioned by Development Bank of South Africa. (Accessed 16 April 2012).

Boughey, C. 2007. Constructing foundation work: A critical discourse analysis of the 2006 submissions for funding. In Conference proceedings: Conversation about Foundation and Extended Curriculum provision ed. J. Garraway, 5-13. Cape Town: Cape Peninsula University of Technology.

ECP Statistics. 2015. Faculty of Business and Management Sciences: CPUT: "Returning students 20142015".

Foxcroft, C. 2006. The nature of benchmark tests. In Access and entry level benchmarks. The National 
Benchmark Tests Project, ed. H. Griesel, 7-14. Pretoria: Higher Education South Africa.

Garraway, J. 2009. Success of Foundation (Extended Programmes) in engineering and sciences. In HELTASA. Success stories in foundation/Extended Programmes. Higher Education Learning and Teaching Association of South Africa (HELTASA).

Griesel, H. 2006. The context of the National Benchmark Tests Project. In Access and entry level benchmarks: The National Benchmark Tests Project, ed. H. Griesel, 1-6. Pretoria: Higher Education South Africa.

HELTASA. 2009. Success stories in Foundation/Extended programmes. Higher Education Learning and Teaching Association of South Africa (HELTASA).

Jones, B., G. Coetze, T. Bailey and S. Wickam. 2008. Factors that facilitate success for selected higher education students: An investigation into approaches used by REAP, NSFAS and selected higher education institutions. Cape Town; Rural Education Access Programme (REAP).

Ogle, M-A. 2010. The impact of a communications intervention on engineering students extended curriculum programme at Cape Peninsula University of Technology: 1-2.

Scholtz, D. and C. O. K. Allen-lle. 2007. Is the SATAP test an indicator of Academic preparedness for first year students? Cape Peninsula University of Technology: Bellville South Africa. South African Journal of Higher Education 21(7): 919-922.

Shay, S., K. Wolff and J. Clarence-Fincham. 2016. New generation extended curriculum programmes: Report to the DHET, iii-iv and 23-24. Cape Town: University of Cape Town.

Van der Flier, H., G. D. Thijs and T. Zaaiman. 2003/6. Selecting students for a South African mathematics and science foundation programme: The effectiveness and fairness of school-leaving examination and aptitude tests. International Journal of Educational Development 23: 399-409.

Yeld, N. 2006. Test domains and constructs. In Access and entry level benchmarks. The National Benchmark Tests Project, ed. H. Griesel, 17-23. Pretoria: Higher Education South Africa. 